\title{
The effect of antibiotics that inhibit cell-wall, protein, and DNA synthesis on the growth and morphology of Legionella pneumophila
}

\author{
F. G. RODGERS, A. O. TZIANABOS and T. S. J. ELLIOTT*
}

Department of Microbiology, Spaulding Life Sciences Center, University of New Hampshire, Durham, New Hampshire 03824, USA and "Department of Clinical Microbiology, Queen Elizabeth Hospital, Queen Elizabeth Medical Centre, Edgbaston, Birmingham B15 2TH

\begin{abstract}
Summary. The response of Legionella pneumophila to antibiotics that inhibit cell-wall, protein and DNA synthesis was examined by electronmicroscopy, MIC estimations and viable counts. Ampicillin, cefotaxime, methicillin, erythromycin, rifampicin and ciprofloxacin, each used separately at 20 times their respective MIC values, showed activity against $L$. pneumophila in these studies. The inhibitors of cell-wall synthesisampicillin, cefotaxime and methicillin-effected the greatest bactericidal activity and induced the most extensive morphological changes, which included the formation of membranous lesions through which cytoplasmic contents were lost. In terms of ultrastructural damage and loss of viability, the inhibitors of protein and DNA synthesis were less effective than the antibiotics that acted on the microbial cell wall. Erythromycin- and rifampicin-treated cells possessed irregular membranes and were partially or fully lysed, whereas ciprofloxacin induced abnormally elongated organisms with intermittently lysed and detached inner membranes. These results illustrated the ability of antibiotics of putative clinical value, with diverse modes of action, to affect the ultrastructural cytology as well as the viability of $L$. pneumophila in vitro.
\end{abstract}

\section{Introduction}

Legionella pneumophila, the causal agent of an often fatal form of pneumonia known as Legionnaires' disease (legionellosis), has been studied by negative stain, thin-section, freeze-etching, and scanning electronmicroscopy. ${ }^{1,2}$ The response of this human pathogen to treatment with antimicrobial chemotherapeutic agents has been investigated by various in-vitro and in-vivo techniques. ${ }^{3-11}$ Although several antibiotics have excellent activity against $L$. pneumophila in vitro, as assessed in studies of minimum inhibitory concentrations (MIC), few show similar results in clinical practice. Erythromycin is currently the drug of choice for the treatment of legionellosis; however, inherent problems arise in its use. Reports of relapse of infection, development of phlebitis with intravenous antibiotic administration, and potential complications related to the emergence of bacterial resistance have been associated with erythromycin therapy. For these reasons, several other antimicrobial agents have been investigated as potential alternatives for clinical use in the treatment of

Received 4 July 1989; accepted 4 Aug. 1989. legionellosis. In this study, we examined the morphological characteristics and growth response of $L$. pneumophila after exposure to antimicrobial agents selected from three groups of either proven or putative clinical value; they included inhibitors of bacterial cell-wall synthesis, protein synthesis and DNA replication. The effects of the agents were evaluated by MIC estimations, viable counts and ultrastructural (electronmicroscopic) investigations.

\section{Materials and methods}

\section{Bacterial strains and growth conditions}

L. pneumophila serogroup 1, strain Nottingham $\mathrm{N}_{7}$, was isolated from a sputum sample from a fatal case of Legionnaires' disease; it was subsequently passaged twice on bacteriological media and maintained frozen in serum sorbitol at $-70^{\circ} \mathrm{C}$. The organism was fully virulent as determined both in infectivity studies in MRC- $5^{12}$ and U-937 cell cultures as well as in a chick embryo virulence assay system. ${ }^{9-13}$ Additional investigations were performed with the laboratory adapted serogroup 3 strain, Bloomington 2. Cultures were grown on buffered charcoal yeast extract agar supplemented with $\alpha$-ketoglutarate $(B C Y E \alpha)^{14}$ or on buffered enriched blood agar as previously described, ${ }^{15}$ at $37^{\circ} \mathrm{C}$ for $48 \mathrm{~h}$. Organisms were 
harvested from plates and inoculated into buffered yeast extract broth supplemented with $\alpha$-ketoglutarate- $(/ \mathrm{L})$ Yeast extract (Difco) $10 \mathrm{~g}$; ACES buffer (Sigma) $10 \mathrm{~g}$; $\alpha$ ketoglutarate (Sigma) $1.0 \mathrm{~g}$; L-cysteine (Sigma) $0.4 \mathrm{~g}$; ferric pyrophosphate (Sigma) $0.25 \mathrm{~g} ; \mathrm{pH}$ adjusted to 6.9 with $\mathrm{KOH}$; filter sterilised through a $0 \cdot 2-\mu \mathrm{m}$ filter $(B Y E \alpha)$ or enriched blood broth (EB) ${ }^{16}$ to give a final concentration of approximately $10^{5}$ organisms $/ \mathrm{ml}$. Organisms were incubated in static culture at $37^{\circ} \mathrm{C}$.

\section{Antibiotics}

Dilutions of ampicillin (sodium salt) (Beecham Pharmaceuticals), cefotaxime (sodium salt) (Hoechst-Roussel Pharmaceuticals), methicillin (sodium salt) (Sigma), erythromycin lactobionate (Abbott Laboratories), rifampicin (Sigma), and ciprofloxacin (Miles Pharmaceuticals) were prepared in either EB broth or in BYE $\alpha$ broth (table). Each antibiotic was added in the mid-logarithmic phase of growth of the test strain to give a final concentration of 20 times the MIC of each antimicrobial agent. These drug concentrations were selected to give valid direct comparisons and to ensure a morphological response, when present, in the entire microbial population. After incubation for 6 and $24 \mathrm{~h}$ in the presence of antibiotics, $5-\mathrm{ml}$ samples were removed from the cultures. Organisms were harvested by centrifugation at $600 g$ for $10 \mathrm{~min}$, washed twice in broth and either serially diluted for viable counts or prepared for electronmicroscopy. Control samples of untreated organisms were harvested and prepared in the same manner.

\section{Viable counts}

Bacterial viable counts were determined in triplicate by inoculating $10-\mu 1$ volumes of 10 -fold serial dilutions of cultures in phosphate-buffered saline on to $B C Y E \alpha$ agar. Resultant colonies were counted and viable counts (cfu/ $\mathrm{ml})$ were determined from those plates containing 30 100 colonies as previously described. ${ }^{3-12}$

Table. Susceptibility of $L$. pneumophila strains $\mathrm{N}_{7}$ and Bloomington 2 to selected antibiotics

\begin{tabular}{llc}
\hline \multicolumn{1}{c}{ Antibiotic } & Growth medium & $\mathrm{MIC}(\mathrm{mg} / \mathrm{L})^{*}$ \\
\hline $\begin{array}{l}\text { Cell wall inhibitors } \\
\text { ampicillin }\end{array}$ & EB broth & 0.4 \\
cefotaxime \\
$\begin{array}{l}\text { methicillin } \\
\begin{array}{l}\text { Protein synthesis inhibitors } \\
\text { erythromycin } \\
\text { rifampicin }\end{array}\end{array}$ & BYE $\alpha$ broth & 8.0 \\
$\begin{array}{l}\text { BNA inhibitor } \\
\text { ciprofloxacin }\end{array}$ & EB broth & 64 \\
& BYE $\alpha$ broth & 0.5 \\
\hline
\end{tabular}
* MIC values for the two strains with each antimicrobial were
within a single doubling dilution.

\section{Electronmicroscopy}

Bacteria were fixed in glutaraldehyde $3 \% \mathrm{v} / \mathrm{v}$ in $0.05 \mathrm{M}$ sodium cacodylate containing $10 \mathrm{mM} \mathrm{MgSO}_{4}{ }^{2}$ For negative stain electronmicroscopy, $25 \mu \mathrm{l}$ of each sample was mixed with an equal volume of phosphotungstic acid $1 \% \mathrm{w} / \mathrm{v}, \mathrm{pH} 6 \cdot 7$, and applied to 400 mesh formvar-carbon coated copper electronmicroscope grids. For scanning electronmicroscopy, samples were applied to specimen stubs, dehydrated in a graded ethanol series, and either critical point dried as previously described ${ }^{3}$ or treated with hexamethyldisilaxane (HMDS) ${ }^{17}$ Before examination, samples were coated with $20 \mathrm{~nm}$ of either gold or gold-palladium in a Balzers or Hummer V sputter coater. For thin-section electronmicroscopy, all samples were dehydrated in an ethanol series and embedded in an epon-araldite mixture. Sections $c .60 \mathrm{~nm}$ thick were cut on an LKB Ultratome III with a diamond knife and stained with uranyl acetate $5 \% \mathrm{w} / \mathrm{v}$ for $1 \mathrm{~min}$ and lead citrate $0.4 \% \mathrm{w} / \mathrm{v}$ for $20 \mathrm{~s} .^{1,2}$

\section{MIC determination}

MICs were determined by a broth dilution method. ${ }^{18}$ Briefly, serial two-fold dilutions of each antibiotic were prepared in EB or BYE $\alpha$ broth and inoculated with cultures in the mid-logarithmic phase of growth to give a final concentration of $10^{5}$ organisms $/ \mathrm{ml}$. The broths were incubated for $16 \mathrm{~h}$ and the lowest concentration of antibiotic which inhibited growth, as determined by naked eye examination, was taken as the MIC.

\section{Results}

\section{Growth and viability studies}

MIC values for the six antibiotics are shown in the table. The growth characteristics and effect on viability of $L$. pneumophila in the presence of the six antibiotics investigated are illustrated in fig. 1. L. pneumophila grown in EB and BYE $\alpha$ broth without antibiotic, had a mean generation time of 2.0 and $1.3 \mathrm{~h}$, respectively. All the antibiotics tested except erythromycin showed excellent activity against $L$. pneumophila throughout the course of these experiments. The inhibitors of bacterial cellwall synthesis-ampicillin, cefotaxime, and methicillin-effected the most rapid decline in viable counts during the first $6 \mathrm{~h}$ of treatment. Of the agents tested, cefotaxime was most effective at reducing organism viability at the times investigated; it also induced the most dramatic morphological changes (see below). Erythromycin was the least active agent tested.

\section{Morphological studies}

Untreated cultures. Negative stain, scanning and thin-section electronmicroscopy studies on normal 


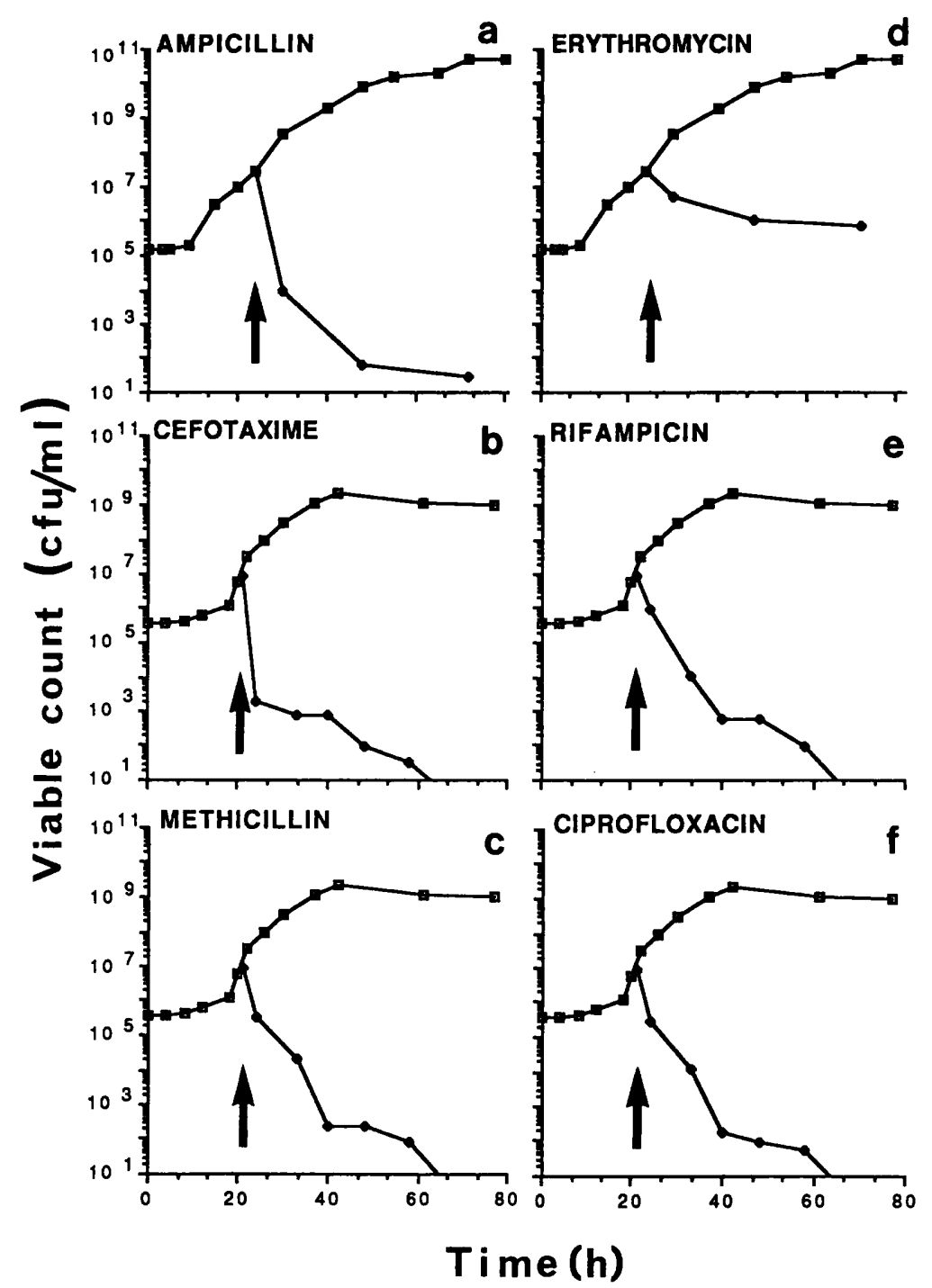

Fig. 1. Growth of L. pneumophila in EB or BYE $\alpha$ broth (see table). The effect on bacterial viability of antimicrobial agents added during the mid-logarithmic phase of growth is shown: $\mathbf{a}, \mathbf{b}, \mathbf{c}$-inhibitors of cell-wall synthesis; $\mathbf{d}$, $\mathrm{e}$-inhibitors of protein synthesis; f-inhibitor of DNA replication. Arrow indicates time of antibiotic addition.

control (untreated) organisms revealed the typical appearance of legionellae. Most cells were 2-10 $\mu \mathrm{m}$ long and $0.25-0.5 \mu \mathrm{m}$ wide. The bacterial surface of normal cells was rugose and ruffled in appearance. The cell-wall structure was consistent with that of gram-negative bacteria. A lipid bilayer, or cytoplasmic membrane, enclosed the cytoplasm which consisted of ribosomes, a small number of intracellular vacuoles and a fine skein of nuclear elements. The latter were distributed evenly throughout the bacterial cytoplasm. The outer membrane enveloped the periplasm which showed little structural evidence of a peptidoglycan layer (fig. 2).
Cultures treated with inhibitors of cell-wall synthesis. (i) Ampicillin. Exposure to ampicillin affected the shape and size of the organisms and induced disruptions in the outer cell envelope. Incubation with 20 times the MIC of ampicillin for $6 \mathrm{~h}$ resulted in the development of vacuole-like lesions in the cell wall and extrusion of the cytoplasmic contents from lytic points in the cell membrane. Further incubation to $24 \mathrm{~h}$ led to the eventual disruption of the cell wall with bacterial lysis and the formation of spheroplasts. Some lysed cells developed numerous membranous vesicles distributed over their surface. Other apparently unaffected legionellae, along with a small number of spherical minicell- 

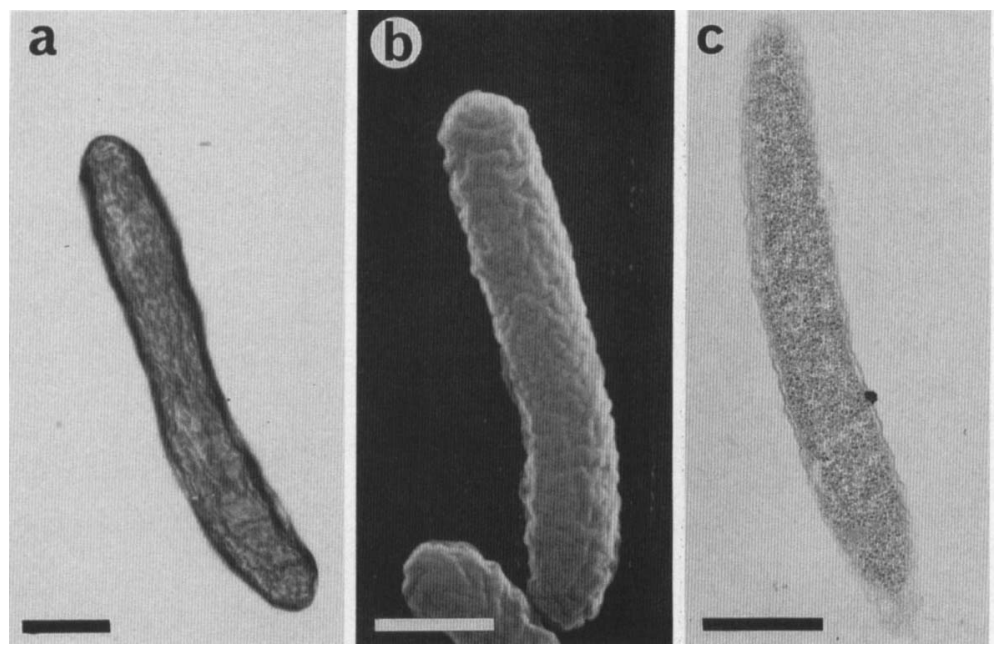

Fig. 2. Electronmicrographs of untreated, control L. pneumophilia organisms: (a) negative stain; (b) scanning; (c) thin-section. Bars $=0.5 \mu \mathrm{m}$.

like organisms of $0 \cdot 15-\mu \mathrm{m}$ diameter, possessed a normal cell-wall structure (fig. 3).

(ii) Cefotaxime. Cefotaxime at 20 times its MIC caused extensive damage to the bacterial cells. Incubation with this antibiotic for $6 \mathrm{~h}$ resulted in the formation of lesions and lytic points in the cell walls of a greater number of bacteria than in the cultures treated with any of the other antibiotics studied at this time. Extrusion of the bacterial cytoplasmic contents through such lytic points was the most common feature noted. Bulbous vesicles were observed on the surface of cells and many organisms possessed diffuse electron-lucent cytoplasmic contents. Extension of treatment with cefotaxime to $24 \mathrm{~h}$ resulted in an increase in damage to these cells in terms of the degree of membranous lesions and vesicles induced in the cell surfaces as well as the number of organisms affected. In addition, many bacteria lacked either cytoplasmic contents of prokaryotic structure. The formation of spheroplasts was not observed (fig. 3).

(iii) Methicillin. Organisms grown in the presence of 20 times the MIC of methicillin showed extensive morphological changes. Affected cells exhibited cell wall and membrane abnormalities and developed several lytic points through which the cytoplasmic contents extruded into the surrounding menstruum. Although many organisms appeared normal, spheroplast formation was evident at this stage. Incubation with methicillin for $24 \mathrm{~h}$ induced a greater degree of cell wall and membrane damage than was evident at $6 \mathrm{~h}$. The outer membrane of the majority of organisms was found to have separated from the remaining cell wall and small vesicles had developed on the cell surfaces. As a consequence of lysis of the inner and outer membranes, there was a loss of cytoplasmic material (fig. 3).

Cultures treated with inhibitors of protein synthesis (i) Erythromycin. Incubation of bacteria with 20 times the MIC of erythromycin resulted in moderate damage to micro-organisms. Short term exposure for $6 \mathrm{~h}$ caused infrequent, random breakpoints in the cell wall. Some elongated, filamentous organisms with numerous vesicles on their surfaces were found in addition to bacteria with bulbous distortions in cell shape. The ribosomal structure of these cells was more prominent, both in size and electron density; this was usually associated with pronounced zones of cytoplasmic clearing. The longer exposure period of $24 \mathrm{~h}$ resulted in an increase in the number of lysed cells, the majority of which retained their bacillary shape despite numerous lytic points in the cell wall. Some cells with an apparently normal morphology were present, but no spheroplasts or minicells were observed (fig. 4).

(ii) Rifampicin. Exposure of L. pneumophila to 20 times the MIC of rifampicin induced marked damage to the bacterial cells. Incubation for $6 \mathrm{~h}$ induced membrane damage, but this appeared less pronounced than with the other antibiotics examined. Separation of outer membranes from the remaining cell wall and breakage points in the inner membranes were evident in affected microorganisms. Furthermore, the ribosomes of these cells were enlarged, electron dense and associated with areas of cytoplasmic clearing. Extended treatment with rifampicin to $24 \mathrm{~h}$ elicited a more 

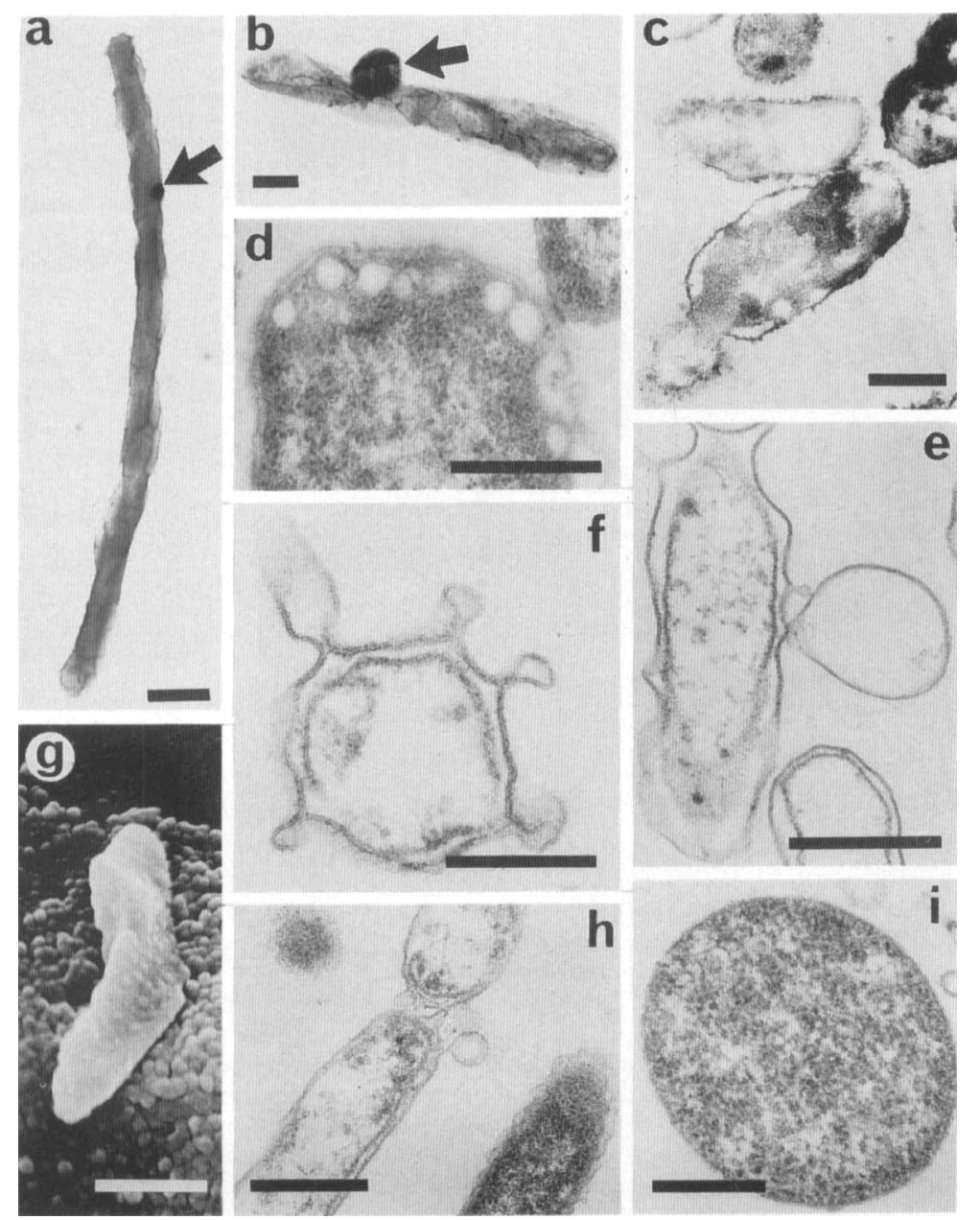

Fig. 3. Electronmicrographs of $L$. pneumophila exposed to the cell-wall inhibitory antibiotics-ampicillin, cefotaxime and methicillin: (a) cefotaxime for $24 \mathrm{~h}$-note partial collapse of organism and initial lytic point (arrow); (b) methicillin for $24 \mathrm{~h}-$ organism has lost cytoplasmic contents through advanced lytic point (arrow); (c) ampicillin for $6 \mathrm{~h}-$ note ruptured bacterial membranes with extrusion of cytoplasmic contents; (d) ampicillin for $24 \mathrm{~h}$-vesicles subjacent to the cytoplasmic membrane were evident; (e) and (f) methicillin for $6 \mathrm{~h}$-distortion, pinching and ballooning of the bacterial outer membranes and loss of cytoplasmic contents were apparent; (g) ampicillin for $24 \mathrm{~h}$-note complete collapse of organism; (h) methicillin for $6 \mathrm{~h}$ - small numbers of normal bacteria were found alongside damaged and partially plasmolysed legionellae; (i) methicillin for $6 \mathrm{~h}-$ spheroplast formation was evident; $\mathbf{a}$ and $\mathbf{b}$, negative stain; $\mathbf{c}, \mathbf{d}, \mathbf{e}, \mathbf{f}, \mathbf{h}, \mathbf{i}$, thin-section; $\mathbf{g}$, scanning electronmicroscopy. $\mathbf{a}-\mathbf{e}, \mathbf{g}, \mathbf{h}, \mathbf{b a r}=0.5 \mu \mathrm{m} ; \mathbf{f}, \mathbf{i}$, bar $=0 \cdot 25 \mu \mathrm{m}$.

pronounced effect in which lytic points in the membrane of cells and loss of intracellular contents led to eventual collapse of the cells (fig. 4).

Cultures treated with an inhibitor of DNA replication: Ciprofloxacin. Organisms treated for $6 \mathrm{~h}$ with 20 times the MIC of ciprofloxacin exhibited marked morphological changes. The majority of cells were abnormally elongated forming filaments, each of which possessed centrally located "pinched zones" suggestive of arrested division. The inner membranes of many legionellae were intermittently lysed and separated from the remaining cell wall material. In addition, the intracellular contents of cells were more densely packed due to an apparent overall increase in the size of individual ribosomes. Further exposure to this antibiotic induced damage to $98 \%$ of the Legionella organisms present. Twisted, convoluted bacteria were found with depressed, partially collapsed areas on their cell surface. Some organisms at this time had lost their intracellular contents through breakage points in the cell wall while others maintained the densely packed cytoplasmic appearance found in organisms treated for $6 \mathrm{~h}$ with this antibiotic (fig. 5). 


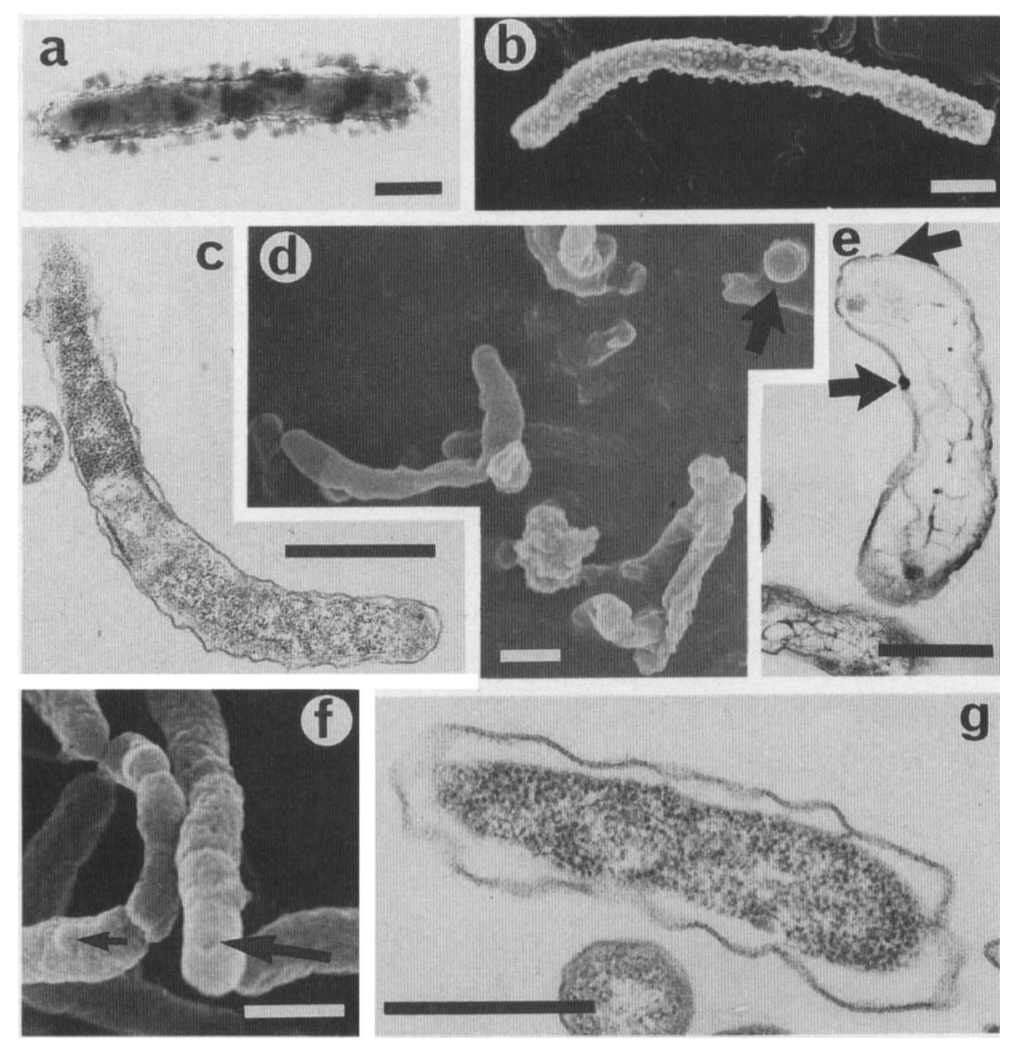

Fig. 4. Electronmicrographs of $L$. pneumophila exposed to inhibitors of protein synthesis -erythromycin and rifampicin: (a) rifampicin for $24 \mathrm{~h}$-darkly staining surface lesions and numerous small membranous vesicles seen; (b) erythromycin for $6 \mathrm{~h}$-note blebs on bacterial outer membrane; (c) rifampicin for $24 \mathrm{~h}$-an increase in the number and density of ribosomes was evident in localised zones within the bacterial cytoplasm; (d) rifampicin for $24 \mathrm{~h}$-note distortion and collapse of organisms and points of lysis (arrow); (e) erythromycin for $24 \mathrm{~h}$-discrete lesions were found in the bacterial membranes in association with loss of cytoplasm (arrows); (f) rifampicin for $6 \mathrm{~h}$-extrusion of cytoplasmic contents was apparent (short arrow) as well as regions of bacterial collapse (long arrow); (g) rifampicin for $24 \mathrm{~h}$-an increase in ribosomal density and disruption of the outer membrane seen; a negative stain; c, e, g, thin-section; b, d, f, scanning electronmicroscopy. Bars $=0.5 \mu \mathrm{m}$.

Fig. 6 shows the relative proportion of lysed and partially damaged cells compared with those of normal morphology following treatment with each antibiotic for 6 and $24 \mathrm{~h}$.

\section{Discussion}

All antibiotics tested were effective against $L$. pneumophila in vitro, as assayed by MIC data, the reduction in bacterial viable counts, and the morphological responses induced. Methicillin showed marked bactericidal activity against multiplying organisms in broth culture. This activity was confirmed by the morphological studies in which many lysed and empty cells were evident after exposure to methicillin for 6 and $24 \mathrm{~h}$. Formation of spheroplasts after treatment with this antibiotic at a concentration of $1280 \mathrm{mg} / \mathrm{L}$ was observed and confirmed our earlier reports of this phenomenon with ampicillin. ${ }^{3}$ Similar spheroplast formation was reported subsequently for methicillin used at a concentration of $100 \mathrm{mg} / \mathrm{L}$ by Chan et al. $;^{5}$ however, unlike the results of the present study, these workers could not demonstrate this phenomenon with increased doses of methicillin up to $1000 \mathrm{mg} /$ $\mathrm{L}$. The addition of magnesium salts to the fixatives and buffers used in our study would have stabilised fragile bacterial membranes and may account for these differences in spheroplast detection.

Cefotaxime showed the greatest bactericidal activity and this resulted in the most rapid decline in numbers of viable organisms. Furthermore, this third generation cephalosporin induced the greatest morphological changes in microbial cytology at both exposure times. These results conflict with 

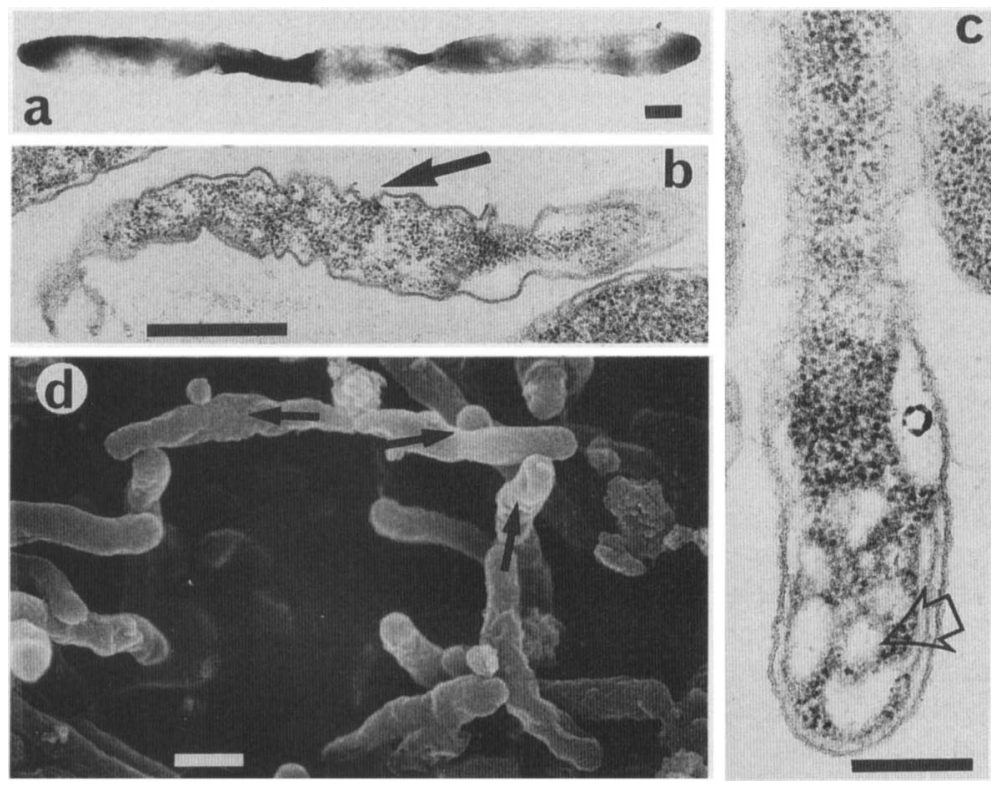

Fig. 5. Electronmicrographs of $L$. pneumophila exposed to the inhibitor of DNA replication, ciprofloxacin: note twisted shape of organisms; convoluted membranes (long arrow); elongation of cells; vesiculation of the microbial cytoplasm (open arrow); distortion, collapse and lysis of bacteria (short arrows); $\mathbf{a}, \mathbf{d}, 24 \mathrm{~h}$ antibiotic exposure; $\mathbf{b}, \mathbf{c}, \mathbf{6} \mathrm{h}$ exposure; $\mathbf{a}$, negative stain; $\mathbf{b}, \mathbf{c}$, thinsection; d, scanning electronmicroscopy; a, b, d, bars $=0.5 \mu \mathrm{m} ; \mathbf{c}$, bar $=0.25 \mu \mathrm{m}$.

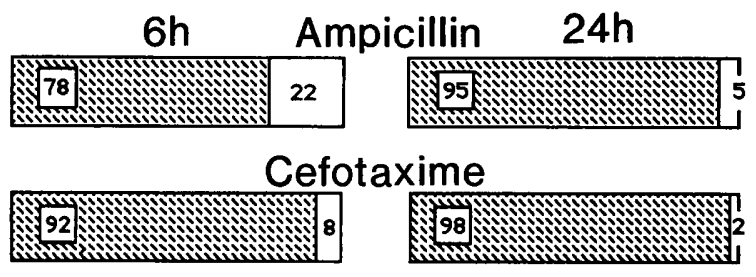

Methicillin

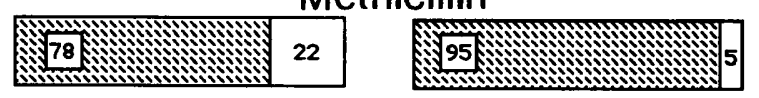

Erythromycin

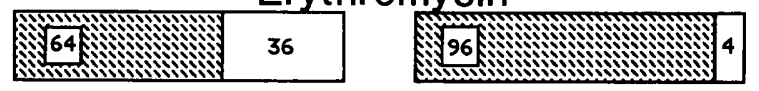

Rifampicin

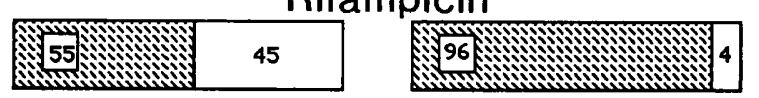

Ciprofloxacin

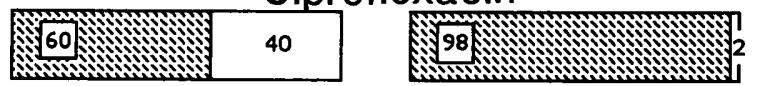

Fig. 6. Proportion of bacterial cells showing normal morphology ( $\square$ ) and those damaged ( $\$$ ) after exposure for 6 or $24 \mathrm{~h}$ to the various antibiotics at 20 times their respective MIC values. Percentages were calculated from counts of 100 or more cells for each agent and for each treatment time. those of Chan et al. ${ }^{5}$ who reported no morphological changes in response to exposure of $L$. pneumophila to different concentrations of this antibiotic. It was interesting to note that this drug failed to induce spheroplast formation in L. pneumophila although a similar finding was reported following treatment of other gram-negative bacteria with increased levels of cephalothin. ${ }^{19}$ That the $\beta$-lactam antibiotics are active against dividing cells is well established. In this study, antibiotics were added in the midlogarithmic phase of growth, which, for L. pneumophila in the two broths selected and with an inoculum of $10^{5}$ organisms $/ \mathrm{ml}$, was achieved $24 \mathrm{~h}$ into the growth cycle. Failure of Chan et al. ${ }^{5}$ to detect morphological changes due to this antibiotic may reflect the growth phase of the organisms at the time of treatment.

Ampicillin and erythromycin had similar MIC values against $L$. pneumophila but showed different bactericidal capabilities in vitro. ${ }^{3,4}$ These data were confirmed by electronmicroscopy which showed a greater number of lysed and damaged cells in cultures grown in the presence of ampicillin. In addition, the formation of minicell-like organisms and spheroplasts was observed following treatment with the inhibitor of cell-wall synthesis, ampicilli... It has been suggested that this may constitute a mechanism by which osmotically protected legi- 
onellae survive within host cells and subsequently revert to vegetative forms on the discontinuation of therapy. These results confirm our earlier studies on this agent but contradict those of Chan et al., ${ }^{5}$ who reported no morphological damage to Legionella organisms after exposure to similar levels of erythromycin in vitro.

Ciprofloxacin and rifampicin showed effective bactericidal activity in viable count estimations at both times studied. Despite showing the greatest activity in MIC assays, these antibiotics induced only moderate structural damage after short term exposure. However, such changes increased with exposure time. That bacterial viability was lost before the induction of extensive ultrastructural damage probably reflected the mode of action of these antimicrobial agents against $L$. pneumophila cells in the logarithmic phase of growth.

Although the six antibiotics investigated in this study showed antimicrobial activity against $L$.

\section{REFERENCES}

1. Rodgers F G. Ultrastructure of Legionella pneumophila. J Clin Pathol 1979; 32: 195-202.

2. Rodgers F G, Davey M R. Ultrastructure of the cell envelope layers and surface details of Legionella pneumophila. J Gen Microbiol 1982; 128: 1547-1557.

3. Elliott T S J, Rodgers F G. Morphological response and growth characteristics of Legionella pneumophila exposed to ampicillin and erythromycin. J Med Microbiol $1985 ; 19$ : 383-390.

4. Rodgers F G, Elliott T S J. Antibiotic killing of Legionella. Lancet $1984 ; 1: 684$.

5. Chan E L, Harris R C, Dalton H P. The effect of antibiotics on the cell morphology of Legionella pneumophila. J Med Microbiol 1987; 23 : 149-154.

6. Thornsberry $\mathrm{C}, \mathrm{Baker} \mathrm{C} \mathrm{N}, \mathrm{K}$ irven $\mathrm{L} \mathrm{A}$. In vitro activity of antimicrobial agents on Legionnaires' disease bacterium. Antimicrob Agents Chemother 1978; 13: 78-80.

7. Havlichek D, Saravolatz L, Pohlod D. Effect of quinolones and other antimicrobial agents on cell-associated Legionella pneumophila. Antimicrob Agents Chemother 1987; 31 : 1529-1534.

8. Vilde J L, Dournon E, Rajagopalan P. Inhibition of Legionella pneumophila multiplication within human macrophages by antimicrobial agents. Antimicrob Agents Chemother 1986; 30: 743-748.

9. Tzianabos A O, Rodgers F G. Pathogenesis and chemotherapy of experimental Legionella pneumophila infection in the chick embryo. Zbl Bakt Hyg (In press).

10. Fitzgeorge R B, Baskerville A, Featherstone A S R. Treatment of experimental Legionnaires' disease by aerosol adminstration of rifampicin, ciprofloxacin, and erythromycin. Lancet 1986; 1: 502-503.

11. Fitzgeorge R B, Gibson D H, Jepras R, Baskerville A. Studies on ciprofloxacin therapy of experimental Legionnaires' disease. J Infect 1985; 10: 194-203.

12. Oldham L J, Rodgers F G. Adhesion, penetration and pneumophila in vitro, it has been reported that the aminoglycosides, cephalosporins, and penicillins, including ampicillin and methicillin, are clinically ineffective in the treatment of legionellosis. ${ }^{20}$ Because of its intracellular nature, L. pneumophila can avoid the effects of antimicrobial agents that cannot penetrate host-cell membranes. Moreover, it has been reported that ciprofloxacin, ${ }^{7}$ erythromycin and rifampicin ${ }^{7,8}$ inhibit intracellular $L$. pneumophila while the $\beta$-lactam antibiotics such as ampicillin, cefoxitin and cefotaxime do not. ${ }^{21}$

In this study, the presence of bacteria with apparently normal morphology following extended incubation with these antibiotics may offer some explanation of clinical treatment failures. Caution should be used in extrapolating apparently acceptable laboratory findings to the development of clinical regimens for the treatment of Legionnaires' disease.

intracellular replication of Legionella pneumophila: an in vitro model of pathogenesis. J Gen Microbiol 1985; 131 : $697-706$.

13. Tzianabos A O, Rodgers F G. Electron microscopy of the pathology and chemotherapy of experimental Legionella pneumophila infection in the chick embryo. $\mathrm{Zbl}$ Bakt Hyg (In press).

14. Edelstein P H. Improved semiselective medium for isolation of Legionella pneumophila from contaminated clinical and environmental specimens. J Clin Microbiol 1981; 14: $298-303$.

15. Dennis P J, Taylor J A, Barrow G I. Phosphate buffered, low sodium chloride blood agar medium for Legionella pneumophila. Lancet 1981; 2: 636.

16. Rodgers F G, Greaves P W, Macrae A D, Lewis M J. Electron microscopic evidence of flagella and pili on Legionella pneumophila. J Clin Pathol 1980; 33: 1184 1188.

17. Nation J L. A new method using hexamethyldisilazane for preparation of soft insect tissues for scanning electron microscopy. Stain Technol 1983; 58: 347-351.

18. Jones R N, Barry A L, Gavan T L, Washington J A. Susceptibility tests: microdilution and macrodilution broth procedures. In : Lennette $\mathrm{E} \mathrm{H}$, Balows A, Hausler W J, Shadomy H J (eds) Manual of Clinical Microbiology, 4th edn. Washington, American Society for Microbiology. 1985: 972-977.

19. Nishino T, Nakazawa S. Bacteriological study on effects of beta-lactam group antibiotics in high concentrations. Antimicrob Agents Chemother 1976; 9: 1033-1042.

20. Kirby B D, Snyder K M, Meyer R D, Finegold S M. Legionnaires' disease: report of sixty-five nosocomial acquired cases and review of the literature. Medicine (Baltimore) 1980; 59: 118-205.

21. Yoshida S, Mizuguchi Y. Antibiotic susceptibility of Legionella pneumophila, Philadelphia-1, in cultured guinea-pig peritoneal macrophages. J Gen Microbiol 1984; 130 : 901-906. 